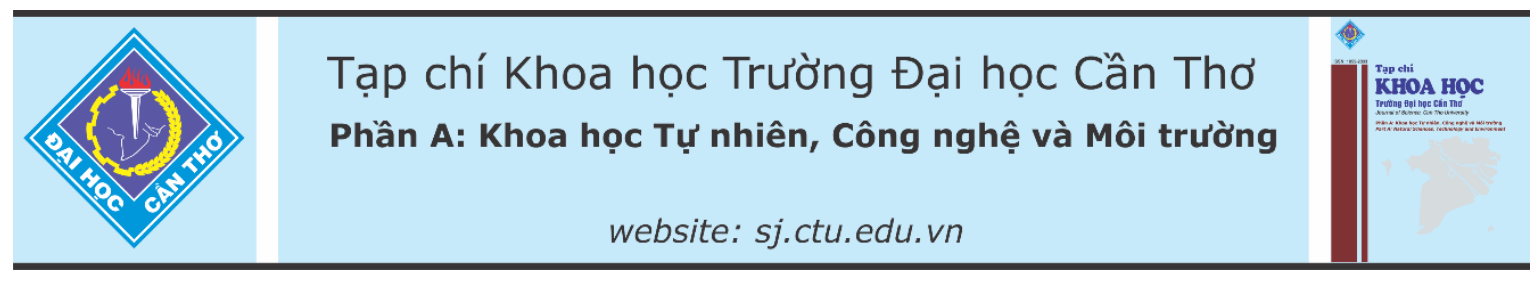

DOI:10.22144/ctu.jvn.2021.008

\title{
THÀNH PHẦN FLAVONOID VÀ HOẠT TÍNH KHÁNG VIÊM CỦA CÂY CAM THẢO NAM Scoparia dulcis
}

\author{
Phạm Thị Nhật Trinh ${ }^{1}$, Tống Thanh Danh ${ }^{2,3}$ và Lê Tiến Dũng ${ }^{4 *}$ \\ ${ }^{1}$ Truờng Đại học Tiền Giang \\ ${ }^{2} B \hat{o}$ môn Kỹ thuật Hóa hũu cơ, Khoa Kỹ thuật Hóa học, Truoòng Đại học Bách Khoa TP.HCM \\ ${ }^{3}$ Đại học Quốc gia Thành phố Hồ Chí Minh \\ ${ }^{4}$ Viện Khoa hoc Vật liệu UÚng dụng \\ *Người chịu trách nhiệm về bài viết: Lê Tiến Dũng (email: inpcdung@yahoo.com)
}

\section{Thông tin chung:}

Ngày nhận bài: 28/12/2020

Ngày nhận bài sửa: 11/01/2021

Ngày duyệt đăng: 27/03/2021

Title:

Flavonoid compounds and anti-inflammatory activity from Scoparia dulcis leaves

\section{Tù khóa:}

Flavonoid, kháng viêm, Scoparia dulcis

\section{Keywords:}

Anti-inflammation, flavonoid, Scoparia dulcis

\begin{abstract}
The medicinal plant Scoparia dulcis is used for the treatment of bronchitis, gastric disorders, antidiabetes, hypertension, hepatitis etc. In this study, experiments were designed to evaluate in vitro the antiinflammatory activity and to isolate phytochemicals from the methanol extract of leaves of Scoparia dulcis. The chemical investigation of this extract, through chromatography method, led to the isolation of two flavonoids, their chemical structures were identified as apigenin 7-Orutinoside (1) and isoquercitrin (2). In the anti-inflammatory assay, crude ethanolic extract and ethyl acetate as well as methanol fractions had potent anti inflammation activity through the inhibition of nitric oxide formation in cells.
\end{abstract}

\section{TÓM TÁ́T}

Cam thảo nam (Scoparia dulcis) được sủ dụng trong điều trị các bệnh về đuờng tiêu hóa, đái tháo đường, cao huyết áp, bảo vệ gan... Nghiên cứu này trình bày kết quả về hoạt tính kháng viêm của cao chiết và quá trình phân lập chất tù̀ lá cam thảo nam. Bằng các phuoong pháp sắc ký, hai flavonoid đã được phân lập và xác định cấu trúc hóa học là apigenin 7 O-rutinoside và isoquercitrin. Trên mô hình kháng viêm thông qua ức chế việc tạo thành nitric oxide, cao chiết cồn tổng, cao phân đoạn ethyl acetate, methanol có tác dụng kháng viêm.

\section{GIỚI THIỆU}

Cam thảo nam có tên khoa học là Scoparia dulcis Linn (Scrophulariaceae), một loại cây sống lâu năm, thường được tìm thấy ở các nước nhiệt đới và cận nhiệt đới trên thế giới. Theo y học dân gian, cây được sử dụng để điều trị viêm phế quản, rối loạn dạ dày, trị đái tháo đường, cao huyết áp, viêm gan ... (Đỗ Tất Lợi, 2004). Kết quả phân tích hóa thực vật cho thấy cây chứa flavonoid, diterpenoid, triterpenoid, sterol, benzoxazinoid (Chen and Chen, 1976; Mahato et al., 1981; Kawasaki et al., 1988; Ahsan et al., 2012; Wu et al., 2012). Về tác dụng dược lý, cam thảo nam thể hiện hoạt tính chống oxy hóa, chống viêm, giảm đau, chống ung thư và đái tháo đường (Latha et al., 2009; Tsai et al., 2011; Wu et al., 2012). Tiếp tục trong nghiên cứu về phân lập và đánh giá hoạt tính sinh học của các hợp chất thiên nhiên trong cây thuốc Việt Nam (Dat et al., 2015; Phan et al., 2016), bài báo này thông báo kết quả về 
phân lập, xác định cấu trúc và đánh giá hoạt tính kháng viêm của cao tổng và cao phân đoạn lá cam thảo nam.

\section{VẬT LIỆU VÀ PHƯƠNG PHÁP NGHIÊN CÚU}

\subsection{Nguyên vật liệu}

Lá cam thảo nam được thu hái tại huyện Vũng Liêm, tỉnh Vĩnh Long. Mẫu nguyên liệu được xác nhận bởi TS. Lưu Hồng Trường, Viện sinh thái học miền Nam. Mẫu tiêu bản (ký hiệu SD-05.2019) được bảo quản tại phòng Hóa sinh dược, Viện khoa học vật liệu ứng dụng.

\subsection{Phương pháp nghiên cứu}

Thiết bị: Phổ NMR được ghi trên máy quang phổ Bruker AM500 FTNMR (Bruker, Karlsruhe, Đức) sử dụng TMS làm chất chuẩn nội, Viện Hóa học (Viện Hàn lâm Khoa học và Công nghệ Việt Nam, Hà Nội, Việt Nam). Sắc ký lớp mỏng được thực hiện trên các tấm silica gel $60 \quad$ F254 (1.05554.0001, Merck, Darmstadt, Đức) pha thường và RP-18 F254S (1.15685.0001, Merck, Darmstadt, Đức) pha đảo. Các vết được phát hiện bằng cách sử dụng UV ở bước sóng 254 hoặc $365 \mathrm{~nm}$ hoặc $\mathrm{H}_{2} \mathrm{SO}_{4}$ / EtOH. Sắc ký cột được thực hiện trên silica gel (240-430 mesh, Merck, Darmstadt, Đức), ODS (70230 mesh, Merck, Darmstadt, Đức) và Sephadex LH-20 (GE Healthcare Bio-Sciences AB, Uppsala, Thụy Điển).

Chiết xuất và phân lập: Lá cam thảo nam $(4,9$ $\mathrm{kg})$ được ngâm với ethanol $96 \%$ (3x12 L). Dịch chiết được thu hồi dung môi trên thiết bị cô quay chân không ở $60^{\circ} \mathrm{C}$, thu được cao tổng $(280 \mathrm{~g})$. Tiến hành sắc ký cột silica gel cao tổng, giải hấp với các đơn dung môi có độ phân cực tăng dần, cô cạn dung môi thu được cao $n$-hexane $(40,8 \mathrm{~g})$, ethyl acetate $(90,8 \mathrm{~g})$ và methanol $(126,7 \mathrm{~g})$. Cao methanol (SDM) được tách phân đoạn trên sắc ký cột silica gel, giải hấp bằng hỗn hợp EtOAc: $\mathrm{MeOH}: \mathrm{H}_{2} \mathrm{O}(25$ : $1: 1 ; 20: 1: 1 ; 10: 1: 1 ; 8: 1: 1$ và $5: 1: 1, \mathrm{v} / \mathrm{v} / \mathrm{v})$ thu được 3 phân đoạn (SDM1-3). Phần SDM2 (21,9 g) được nạp vào cột silica gel và rửa giải bằng $\mathrm{CHCl}_{3}$ : $\mathrm{MeOH}(30: 1 ; 10: 1$ và $8: 1, \mathrm{v} / \mathrm{v})$ thu được tám phân đoạn (SDM2.1-8). Phân đoạn SDM2.7 tiếp tục được sắc ký trên cột silica gel rửa giải bằng $\mathrm{CHCl}_{3}$ : $\mathrm{MeOH}(8: 1 ; 5: 1, \mathrm{v} / \mathrm{v})$ cho ra sáu phân đoạn con (SDM2.7.1-6).

Phân đoạn SDM2.7.3 được cho vào cột ODS sử dụng $\mathrm{MeOH}: \mathrm{H}_{2} \mathrm{O}$ (1:3) làm chất rửa giải để tạo ra bảy phân đoạn (SDM2.7.3.1-7). Phân đoạn SDM2.7.3.1 được tinh chế qua sephadex LH20 $(\mathrm{MeOH})$, phân đoạn có màu vàng được nạp vào cột silica gel, rửa giải bằng $\mathrm{CHCl}_{3}: \mathrm{MeOH}(6: 1)$ để thu được $1(18,0 \mathrm{mg})$. Tiếp tục tách phân đoạn SDM2.7.3.5 trên cột Sephadex LH-20 với $\mathrm{MeOH}$ làm chất rửa giải và sau đó là cột $\mathrm{ODS}$ rửa giải với MeOH: H2O (1: 1) thu được 2 (22 mg).

Hợp chất 1: chất bột vô định hình màu vàng; Phổ ${ }^{1} \mathbf{H}$ NMR $\left(\mathrm{CD}_{3} \mathrm{OD}, 500 \mathrm{MHz}\right), \delta_{\mathrm{H}} \mathrm{ppm}(\mathrm{J}, \mathrm{Hz})$ : 7,73 (2H, d, 9,0 Hz, H-2'/H-6'), 6,69 (2H, d, 9,0 Hz, H-3'/H-5'), 5,04 (1H, d, 7,0 Hz, H-1' '), 3,32 (1H, m, H-2"'), 3,36 (1H, m, H-3"'), 3,41 (1H, m, H-4"'), 3,52 (1H, m, H-5' '), 4,06 (1H, d, 9,5 Hz, H-6''a), 3,68 (1H, m, H-6'"e), 4,74 (1H, s, H-1 ', '), 3,66 (1H, m, H-2"' '), 3,49 (1H, m, H-3"' '), 3,33 (1H, m,H4",'), 3,47 (1H, m, H-5"', ), 1,20 (3H, d, 6,5 Hz, H6"'). Phổ ${ }^{13}$ C NMR $\left(\mathrm{CD}_{3} \mathrm{OD}, 125 \mathrm{MHz}\right): \delta_{\mathrm{C}} \mathrm{ppm}$ : 168,5 (C-2), 101,2 (C-3), 183,6 (C-4), 162,5 (C-5), 101,0 (C-6), 164,3 (C-7), 96,1 (C-8), 158,8 (C-9), 106,9 (C-10), 120,8 (C-1'), 129,7 (C-2'/C-6'), 120,5 (C-3'/C-5'), 164,2 (C-4'), 100,8 (C-1'”), 74,8 (C2'), 77,8 (C-3'), 71,3 (C-4'), 77,1 (C-5'), 67,4 (C-6'), 100,8 (C-1'"'), 72,3 (C-2'"'), 72,0 (C-3'"'), 74,0 (C-4"'), 69,7 (C-5'"'), 17,8 (C-6"'').

Hợp chất 2: chất bột vô định hình màu vàng; Phổ ${ }^{1} \mathbf{H}$ NMR (DMSO- $\left.d_{6}, 500 \mathrm{MHz}\right), \delta_{\mathrm{H}} \mathrm{ppm}(\mathrm{J}$, $\mathrm{Hz})$ : 6,19 (d, 2,0 Hz, H-6), 6,40 (d, 2,0 Hz, H-8), 7,55 (brs, H-2'), 6,83 (d, 9,0 Hz, H-5'), 7,56 (br d, 9,0 Hz, H-6'), 12,61 (s, 5-OH), 5,44 (d, 7,0 Hz, H1' '), 3,32 (m, H-2''), 3,08 (m, H-3'), 3,22 (m, H4'), 3,42 (m, H-5'"), 3,55 (m, H-6a'), 3,47 (m, H$6 \mathrm{~b}$ "). Phổ ${ }^{13} \mathbf{C}$ NMR (DMSO- $d_{6}, 125 \mathrm{MHz}$ ): $\delta_{\mathrm{C}}$ ppm: 157,3 (C-2), 134,1 (C-3), 178,2 (C-4), 161,8 (C-5), 99,6 (C-6), 164,9 (C-7), 94,6 (C-8), 157, 2 (C9), 104,8 (C-10), 122,0 (C-1'), 117,0 (C-2'), 145,4 (C-3'), 149,1 (C-4'), 116,2 (C-5'), 122,6 (C-6'), 101,7 (C-1'), 74,8 (C-2''), 77,8 (C-3''), 70,4 (C4'), 77,0 (C-5'), 61,5 (C-6"').

Đánh giá hoạt tính kháng viêm: Hoạt tính kháng viêm được đánh giá thông qua tác dụng ức chế sản sinh NO. Tế bào đại thực bào RAW264.7 thu nhận từ tủy xương chuột được cấy vào đĩa nuôi cấy 96 giếng với mật độ thích hợp. U trong 3 giờ, sau đó được xử lý với cao thử hoặc chất tinh khiết có nồng độ khác nhau trong 30 phút. Sau đó, không hoặc bổ sung chất kích hoạt phản ứng viêm lipopolysaccharide (LPS) nồng độ $1 \mu \mathrm{g} / \mathrm{mL}$, ủ trong 24 giờ ở $37^{\circ} \mathrm{C}, 5 \% \mathrm{CO}_{2}$. Sau 24 giờ, lấy $100 \mu \mathrm{L}$ môi trường nuôi cấy trong mỗi giếng chuyển sang một đĩa Elisa, bổ sung $100 \mu \mathrm{L}$ thuốc thử Griess, đo độ hấp thu ở bước sóng $450 \mathrm{~nm}$ để xác định lượng NO. Định lượng NO: Lấy dịch đồng thể, bổ sung $1 \%$ albumin huyết thanh bò. Lấy $1 \mathrm{~mL}$ hỗn dịch, thêm 1 $\mathrm{mL}$ thuốc thử Griess (1\% sulfanilamide trong 
phosphoric acid $5 \%$ và $0,1 \%$ N- [1- Napthyl]Ethylenediamin), trộn đều và đo độ hấp thu của dung dịch ở $450 \mathrm{~nm}$. Lượng nitric oxide (NO) được suy ra từ đường cong chuẩn của natri nitrit.

\section{KẾT QUẢ VÀ THẢO LUẬN}

Hợp chất 1 thu được ở dạng bột màu vàng. Phổ ${ }^{1} \mathrm{H}$ NMR (MeOD, $500 \mathrm{MHz}$ ) xuất hiện tín hiệu của 1 vòng benzen 2 lần thế tại vị trí $1,4\left[\delta_{\mathrm{H}} 7,73(2 \mathrm{H}, \mathrm{d}\right.$, $9,0 \mathrm{~Hz}, \mathrm{H}-2$ ' và $\mathrm{H}-6$ ') và $6,69(2 \mathrm{H}, \mathrm{d}, 9,0 \mathrm{~Hz}, \mathrm{H}-3$ ' và $\left.\mathrm{H}^{-} 5^{\prime}\right)$ ], một vòng benzen 4 lần thế tại vị trí 1,2,3,5 [ $\delta_{\mathrm{H}} 6,47(1 \mathrm{H}, \mathrm{s}, \mathrm{H}-5)$ và $\left.6,67(1 \mathrm{H}, \mathrm{s}, \mathrm{H}-8)\right]$, một proton olefin cô lập tại $\delta_{\mathrm{H}} 6,48(1 \mathrm{H}, \mathrm{s}, \mathrm{H}-3), 2$ proton anomer tại $\left[\delta_{\mathrm{H}} 5,04(1 \mathrm{H}, \mathrm{d}, 7,0 \mathrm{~Hz}, \mathrm{H}-1\right.$ "') và 4,74 (1H, s, H-1"')], một nhóm methyl bậc ba $\delta_{\mathrm{H}} 1,20$ ( $3 \mathrm{H}, \mathrm{d}, 6,5 \mathrm{~Hz}, \mathrm{H}-6$ " '), một nhóm oxymethylen $\left[\delta_{\mathrm{H}}\right.$ 4,06 (1H, d, 9,5 Hz, $\mathrm{H}_{\mathrm{a}}-6$ ' ') và $3,68\left(1 \mathrm{H}, \mathrm{m}, \mathrm{H}_{\mathrm{b}}-6\right.$ ' $\left.)\right]$ cùng các tín hiệu oxymethine trong vùng 3,32-3,92 ppm. Phổ ${ }^{13} \mathrm{C}$ NMR kết hợp với kỹ thuật DEPT cho thấy, hợp chất 1 có 27 carbon bao gồm 15 carbon $\mathrm{sp}^{2}$ của khung flavonoid $\left[\delta_{\mathrm{C}} 168,5(\mathrm{C}-2), 101,2\right.$ (C3), 183,6 (C-4), 162,5 (C-5), 101,0 (C-6), 164,3 (C7), 96,1 (C-8), 158,8 (C-9), 106,9 (C-10), 120,8 (C$\left.1^{\prime}\right), 129,7$ (C-2' và $\mathrm{C}-6$ '), 120,5 (C-3' và $\left.\mathrm{C}-5^{\prime}\right)$ và $\left.164,2\left(\mathrm{C}-4^{\prime}\right)\right]$ cùng 12 carbon của 2 phân tử đường [ $\delta_{\mathrm{C}} 100,8$ (C-1'), 74,8 (C-2'”), 77,8 (C-3'"), 71,3 (C-4" '), 77,1 (C-5'") và 67,4 (C-6" $)]$, và $101,0(\mathrm{C}-$ 1'"'), 72,3 (C-2"'), 72,0 (C-3'”'), 74,0 (C-4','), 69,7 (C-5" "), 17,8 (C-6"')]. Dựa vào việc tín hiệu nhóm carbonyl xuất hiện tại 183,6 ppm trên phổ ${ }^{13} \mathrm{C}$ NMR và trên phổ $\mathrm{HMBC}$, proton olefin cô lập $\delta_{\mathrm{H}} 6,48$ cho tương quan với carbon carbonyl, khẳng định đây là một flavonoid kiểu khung flavone.

Phổ ${ }^{13} \mathrm{C}$ NMR cho biết $\mathbf{1}$ có 5 carbon bậc ba mang oxy, trừ 2 carbon mang oxy của khung flavone, trong cấu trúc phải mang ba nhóm hydroxyl nữa. Các tín hiệu proton và carbon của vòng benzen 2 lần thế xuất hiện trùng nhau trên phổ NMR xác nhận đây phải là vòng $\mathrm{B}$ của flavone và có cấu trúc đối xứng. Do vậy C-4' phải mang nhóm hydroxyl. Hai proton ghép meta còn lại phải thuộc vòng $\mathrm{A}$ và gắn vào $\mathrm{C}-6 / \mathrm{C}-8$ hoặc $\mathrm{C}-5 / \mathrm{C}-7$. Phổ $\mathrm{HMBC}$ không ghi nhận tương quan giũa 2 proton trên với $\mathrm{C}-4$, xác định 2 proton trên gắn vào $\mathrm{C}-6$ và $\mathrm{C}-8$. Tương quan HMBC giữa $\mathrm{H}-6$ và $\mathrm{H}-8$ với tín hiệu tại $\delta_{\mathrm{C}} 164,3$ ắt hẳn là $\mathrm{C}-8$. Vậy nhóm hydroxyl còn lại gắn vào $\mathrm{C}-5$ có độ dịch chuyển hóa học $\delta_{\mathrm{C}} 162,5$. Giá trị phổ $\mathrm{NMR}$ cho thấy 2 phân tử đường lần lượt là $\beta-\mathrm{D}$ glucose và $\alpha$-L-rhamnose. Tương quan giữa proton anomer của rhamnose $\delta_{\mathrm{H}} 4,74(1 \mathrm{H}, \mathrm{s}, \mathrm{H}-1$ ',') với C-
6" của glucose và proton anomer của glucose $\delta_{\mathrm{H}}$ $5,04(1 \mathrm{H}, \mathrm{d}, 7,0 \mathrm{~Hz}, \mathrm{H}-1$ ' ') với C-7 khẳng định phân tử rhamnose liên kết với glucose tại C-6" và glucose gắn vào khung flavone tại $\mathrm{C}-7$ thông qua liên kết $\mathrm{O}$ glycoside.

Từ các nhận định nêu trên, kết hợp với tài liệu đã công bố (Kokotkiewicz et al. 2012), hợp chất 1 được xác định là apigenin 7-O-rutinoside hay 4',5,7trihydroxyfavone 7-O-rutinoside (isorhoifolin).

Hợp chất 2 có dạng bột màu vàng, cho phản ứng dương tính với thuốc thử $1 \% \mathrm{FeCl}_{3} / \mathrm{EtOH}$. Phổ ${ }^{1} \mathrm{H}$ NMR xuất hiện các tín hiệu cộng hưởng của 1 nhóm $-\mathrm{OH}$ kiềm $\left[\delta_{\mathrm{H}} 12,61(1 \mathrm{H}, s, 5-\mathrm{OH})\right], 1$ vòng benzene thế $1,2,3,5\left[\delta_{\mathrm{H}} 6,40(1 \mathrm{H}, d, J=2,0 \mathrm{~Hz}, \mathrm{H}-8)\right.$ và 6,19 $(1 \mathrm{H}, d, J=2,0 \mathrm{~Hz}, \mathrm{H}-6)], 1$ vòng benzene thế $1,3,4$ [ $\delta_{\mathrm{H}} 77,56(1 \mathrm{H}, b r d, 9,0 \mathrm{~Hz}, \mathrm{H}-6$ '); 7,55 $(1 \mathrm{H}, b r s$, $\left.\mathrm{H}-2^{\prime}\right)$ và $\left.6,83\left(1 \mathrm{H}, d, 9,0 \mathrm{~Hz}, \mathrm{H}-5^{\prime}\right)\right], 1$ phân tử đường $\beta$-glucose $\left[\delta_{\mathrm{H}} 5,44(1 \mathrm{H}, d, 7,0 \mathrm{~Hz}, \mathrm{H}-1\right.$ ' '); 3,55 (1H, m, H-6a'); 3,47 (1H, m, H-6b'); 3,42 (1H, $m, \mathrm{H}-5$ ' '); 3,32 (1H, $m, \mathrm{H}-2$ ' '); 3,22 (1H, $m, \mathrm{H}-$ 4"') và $3,08\left(1 \mathrm{H}, \mathrm{m}, \mathrm{H}-3\right.$ '”)]. Phổ ${ }^{13} \mathrm{C}$ NMR kết hợp kĩ thuật DEPT xuất hiện 21 tín hiệu cộng hưởng gồm 6 tín hiệu cộng hưởng của phân tử đường $\beta$-glucose [ $\delta_{\mathrm{C}} 101,7$ (C-1'); 77,8 (C-3'); 77,0 (C-5'); 74,8 (C-2'); 70,4 (C-4'”) và 61,5 (C-6')], và 15 tín hiệu cộng hưởng của phần aglycone gồm 1 carbon carbonyl nhóm chức ketone [ $\delta_{\mathrm{C}} 178,2$ (C-4)], 7 carbon $s p^{2}$ bậc bốn mang oxygen $\left[\delta_{\mathrm{C}} 164,9(\mathrm{C}-7)\right.$; 161,8 (C-5); 157,3 (C-2); 157,2 (C-9); 149,1 (C-4'); $145,4\left(\mathrm{C}^{3}{ }^{\prime}\right)$ và $\left.134,1(\mathrm{C}-3)\right], 5$ carbon $s p^{2}$ bậc ba $\left[\delta_{\mathrm{C}}\right.$ 122,6 (C-6'); 117,0 (C-2'); 116,2 (C-5'); 99,6 (C-6) và $94,6(\mathrm{C}-8)]$ và 2 carbon $s p^{2}$ bậc bốn $\left[\delta_{\mathrm{C}} 122,0(\mathrm{C}\right.$ 1 ') và 104,8 (C-10)].

Số liệu phổ NMR cho dự đoán 2 có khung flavone. Tín hiệu cộng hưởng ở $\delta_{\mathrm{H}} 12,61$ trên phổ ${ }^{1} \mathrm{H}$ NMR khẳng định nhóm $-\mathrm{OH}$ phải gắn vào $\mathrm{C}-5$. Phổ HMBC xuất hiện tương quan của nhóm - $\mathrm{OH}$ kiềm nối với một carbon $s p^{2}$ bậc ba ở $\delta_{\mathrm{C}} 99,6$ khẳng định đây là C-6. Proton H-6 ở $\delta_{\mathrm{H}} 6,19(d, J=2,0 \mathrm{~Hz})$ ghép meta với proton ở $\delta_{\mathrm{H}} 6,40(d, J=2,0 \mathrm{~Hz})$, nên proton này chỉ có thể là $\mathrm{H}-8$. Các proton vòng $\mathrm{B}$ ứng với vòng benzene 3 lần thế tại vị trí $1,3,4\left[\delta_{\mathrm{H}} 7,56(1 \mathrm{H}\right.$, $\left.b r d, 9,0 \mathrm{~Hz}, \mathrm{H}-6^{\prime}\right) ; 7,55\left(1 \mathrm{H}, b r s, \mathrm{H}-2^{\prime}\right.$ ') và 6,83 $\left.\left(1 \mathrm{H}, d, 9,0 \mathrm{~Hz}, \mathrm{H}-5^{\prime}\right)\right]$. Phổ HMBC cho thấy tương quan giữa proton anomer của phân tử $\beta$-glucose $\delta_{\mathrm{H}}$ $5,44\left(1 \mathrm{H}, d, J=7,0 \mathrm{~Hz}, \mathrm{H}-1\right.$ " ) với carbon C-3 tại $\delta_{\mathrm{C}}$ 134,1 ppm xác nhận phân tử đường glucose gắn vào khung flavone tại C-3. Từ các biện luận trên, hợp chất $\mathbf{2}$ được xác định là isoquercitrin. 


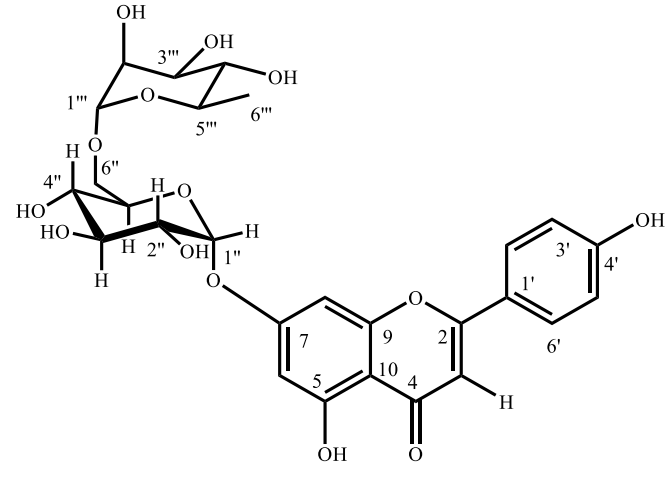

1<smiles>O=c1c(OC(O)CCO)c(-c2ccc(O)c(O)c2)oc2cc(O)cc(O)c12</smiles>

2

Hình 1. Cấu trúc hợp chất 1 và 2

Kết quả đánh giá hoạt tính kháng viêm của các cao chiết và cao phân đoạn được thể hiện trong bảng 1. Trong số các cao thử nghiệm, cao cồn tổng (SDEt), cao chiết phân đoạn ethyl acetate (SDEA) và cao chiết methanol $(\mathrm{SDM})$ có tác dụng kháng viêm ở nồng độ thấp. Trong 3 cao chiết thu được từ phân đoạn methanol, cao chiết SDM2 có tác dụng kháng viêm mạnh nhất. Các kết quả trên cho thấy cam thảo nam có tiềm năng trong việc phát triển các thuốc kháng viêm.

Bảng 1. Kết quả đánh giá tác dụng kháng viêm của các cao chiết

\begin{tabular}{|c|c|c|c|c|}
\hline STT & Tên mẫu & Nồng độ mẫu & $\begin{array}{r}\text { Tỷ lệ ức chế sản sinh } \\
\text { NO }(\%) \\
\end{array}$ & $\begin{array}{r}\text { Tỷ lệ tế bào sống sót } \\
(\%)\end{array}$ \\
\hline & Đối chứng (-) & - & $100,00 \pm 0,4$ & $116,53 \pm 2,0$ \\
\hline & Đối chứng (+) & $0,3 \mu \mathrm{M}$ & $17,10 \pm 0,8$ & $85,82 \pm 0,1$ \\
\hline & [Cardamonin] & $3,0 \mu \mathrm{M}$ & $96,60 \pm 0,6$ & $85,85 \pm 0,1$ \\
\hline & LPS & - & $0,00 \pm 0,8$ & $100,0 \pm 1,5$ \\
\hline \multirow{3}{*}{1} & \multirow{3}{*}{ SDEt } & $100 \mu \mathrm{g} / \mathrm{mL}$ & $97,33 \pm 0,4$ & $38,48 \pm 1,0$ \\
\hline & & $30 \mu \mathrm{g} / \mathrm{mL}$ & $56,90 \pm 0,84$ & $68,35 \pm 1,0$ \\
\hline & & $3 \mu \mathrm{g} / \mathrm{mL}$ & $31,51 \pm 0,7$ & $91,18 \pm 0,9$ \\
\hline \multirow{3}{*}{2} & \multirow{3}{*}{ SDM } & $100 \mu \mathrm{g} / \mathrm{mL}$ & $98,06 \pm 2,1$ & $63,17 \pm 1,2$ \\
\hline & & $30 \mu \mathrm{g} / \mathrm{mL}$ & $47,65 \pm 0,5$ & $78,34 \pm 0,9$ \\
\hline & & $3 \mu \mathrm{g} / \mathrm{mL}$ & $38,71 \pm 0,9$ & $86,41 \pm 0,4$ \\
\hline \multirow{3}{*}{3} & \multirow{3}{*}{ SDH } & $100 \mu \mathrm{g} / \mathrm{mL}$ & $76,72 \pm 0,4$ & $95,85 \pm 0,9$ \\
\hline & & $30 \mu \mathrm{g} / \mathrm{mL}$ & $27,44 \pm 0,7$ & $103,80 \pm 2,1$ \\
\hline & & $3 \mu \mathrm{g} / \mathrm{mL}$ & $17,84 \pm 0,3$ & $102,11 \pm 1,7$ \\
\hline \multirow{3}{*}{4} & \multirow{3}{*}{ SDEA } & $100 \mu \mathrm{g} / \mathrm{mL}$ & $82,95 \pm 0,2$ & $33,42 \pm 1,5$ \\
\hline & & $30 \mu \mathrm{g} / \mathrm{mL}$ & $74,72 \pm 0,6$ & $58,56 \pm 0,5$ \\
\hline & & $3 \mu \mathrm{g} / \mathrm{mL}$ & $26,30 \pm 0,4$ & $94,60 \pm 1,9$ \\
\hline \multicolumn{5}{|c|}{ Cao phân đoạn tù̀ methanol } \\
\hline \multirow{3}{*}{5} & \multirow{3}{*}{ SDM2 } & $30 \mu \mathrm{g} / \mathrm{mL}$ & $90,76 \pm 0,7$ & $73,82 \pm 1,3$ \\
\hline & & $10 \mu \mathrm{g} / \mathrm{mL}$ & $58,92 \pm 0,3$ & $85,77 \pm 0,7$ \\
\hline & & $3 \mu \mathrm{g} / \mathrm{mL}$ & $41,62 \pm 0,9$ & $91,26 \pm 1,1$ \\
\hline \multirow{3}{*}{6} & \multirow{3}{*}{ SDM3 } & $100 \mu \mathrm{g} / \mathrm{mL}$ & $99,54 \pm 0,9$ & $43,15 \pm 1,5$ \\
\hline & & $30 \mu \mathrm{g} / \mathrm{mL}$ & $52,16 \pm 0,6$ & $80,07 \pm 1,1$ \\
\hline & & $3 \mu \mathrm{g} / \mathrm{mL}$ & $28,68 \pm 0,2$ & $87,93 \pm 1,3$ \\
\hline \multirow{3}{*}{7} & \multirow{3}{*}{ SDM1 } & $100 \mu \mathrm{g} / \mathrm{mL}$ & $93,41 \pm 0,6$ & $35,11 \pm 0,2$ \\
\hline & & $30 \mu \mathrm{g} / \mathrm{mL}$ & $55,46 \pm 0,2$ & $63,71 \pm 1,0$ \\
\hline & & $3 \mu \mathrm{g} / \mathrm{mL}$ & $28,38 \pm 0,9$ & $91,48 \pm 0,5$ \\
\hline
\end{tabular}

\section{KẾT LUẬN}

Cao cồn tổng (SDEt), cao chiết phân đoạn ethyl acetate (SDEA) và cao chiết methanol (SDM) của lá cam thảo nam có tác dụng kháng viêm ở nồng độ thấp. Cao chiết SDM2 thu được từ phân đoạn methanol thể hiện tác dụng kháng viêm mạnh nhất. 
Từ cao SDM2, bằng phương pháp sắc ký cột với các chất hấp phụ khác nhau, 2 chất thuộc khung flavone đã được phân lập. Dựa trên các dữ liệu phổ NMR, 2 chất trên được xác định cấu trúc là isorhoifolin (1) và isoquercitrin (2).

Lời Cảm ơn: Công trình được tài trợ bởi Viện Hàn lâm Khoa học và Công nghệ Việt Nam trong đề tài mã số NCVCC19.03/20-20.

\section{TÀI LIẸU THAM KHẢO}

Ahsan, M., Haque, M.R., Islam, S.K.N., Gray, A.I. \& Hasan, C.M. (2012). New labdane diterpenes from the aerial parts of Scoparia dulcis. Phytochemistry Letters, 5(3), 609-612.

Chen, C.M. \& Chen, M.T. (1976). 6Methoxybenzoxazolinone and triterpenoids from roots of Scoparia dulcis. Phytochemistry, 15(12), 1997-1999.

Dat, B.T. Phat, N.T., Hoa, L.T.V., Tri, M.D., Dung, L.T. \& Minh, P.N. (2015). Two new oleananetype triterpene saponins from the leaves of Schefflera sessiliflora De. P. V. Phytochemistry Letters, 11, 102-105.

Đỗ Tất Lợi (2004). Những cây thuốc và vị thuốc Việt Nam. Nhà xuất bản Y học, 871-872.

Kawasaki, M., Hayashi, T., Arisawa, M., Morita, N. \& Berganza, L.H. (1988). 8-Hydroxytricetin 7glucuronide, a $\beta$-glucuronidase inhibitor from Scoparia dulcis. Phytochemistry, 27(11), 3709-3711.

Kokotkiewicz, A., Luczkiewicz, M., Sowinski, P., Glod, D., Gorynski, K. \& Bucinski, A. (2012).
Isolation and structure elucidation of phenolic compounds from Cyclopia subternata Vogel (honeybush) intact plant and in vitro cultures. Food Chemistry, 133(4),1373-1382.

Latha, M., Pari, L., Ramkumar, K.M., Rajaguru, P., Suresh, T., Dhanabal, T., Sitasawad, S. \& Bhonde, R. (2009). Antidiabetic effects of scoparic acid D isolated from Scoparia dulcis in rats with streptozotocin-induced diabetes. Natural Products Research, 23(16), 1528-1540.

Mahato, S.B., Das, M.C. \& Sahu, N.P. (1981). Triterpenoids of Scoparia dulcis. Phytochemistry, 20(1), 171-173.

Phan, N.M. , Nguyen, T.P. , Le, T.D. Chi, M.T., Phong, M.T., \& Tri, M.D. (2016). Two new flavonol glycosides from the leaves of Cleome viscosa L. Phytochemistry Letters, 18, 10-13.

Trinh, P.T.N., Tri, M.D., Hien, D.C., An, N.H., Minh, P.N., An, P.N. \& Dung, L.T. (2016). A new flavan from the Drynaria bonii $\mathrm{H}$. Christ rhizomes. Natural Products Research, 30(7), 761-767.

Tsai, J.C., Peng, W.H., Chiu, T.H., Lai, S.C. \& Lee, C.Y. (2011). Anti-inflammatory effects of Scoparia dulcis L. and betulinic acid. The American Journal of Chinese Medicine, 39(5), 943-956.

Wu, W.H., Chen, T.Y., Lu, R.W., Chen, S.T. \& Chang C.C. (2012). Benzoxazinoids from Scoparia dulcis (sweet broomweed) with antiproliferative activity against the DU-145 human prostate cancer cell line. Phytochemistry, $83,110-115$. 